\title{
ANALYSIS OF AQI CHANGE CHARACTERISTICS AND CORRELATION WITH PM2.5 AND PM10 IN BEIJING-TIANJIN-HEBEI REGION
}

\author{
Anna Wang ${ }^{1}$, Juanli Jing ${ }^{1,2, *}$, Fulin Luo ${ }^{1}$, Lisi Liang ${ }^{1}$ \\ ${ }^{1}$ College of Geomatics and Geoinformation, Guilin University of Technology \\ ${ }^{2}$ Guangxi Key Laboratory of Spatial Information and Geomatics, Guilin 541004,China
}

\section{Commission VI, WG VI/4}

KEY WORDS: AQI; Beijing-Tianjin-Hebei; PM2.5; PM10;Temporal and Spatial Change

\begin{abstract}
:
The paper analyzed the variation characteristics of AQI and its correlation with PM2.5 and PM10 of in Beijing-Tianjin-Hebei region from July 2015 to July 2018 based on hours of pollutants in Beijing-Tianjin-Hebei region, using AQI calculation method and statistical correlation evaluation method. Results showed that:(1) The air quality compliance rate in Beijing-Tianjin-Hebei region was $67 \%$, the average AQI was 97.6577, and the air quality was good. The distribution frequency of primary pollutants was PM2.5, followed by PM10, which accounts for $78.9 \%$ of the distribution frequency of the six major pollutants, indicated that PM2.5 and PM10 had a greater impact on the air quality of Beijing-Tianjin-Hebei. (2) The correlation between AQI and PM2.5 and PM10 was significantly positively correlated. R2 was 0.8225 and 0.7749 , respectively, $\mathrm{P}<0.01$, indicated that both showed a greater impact on air quality. (3) AQI and PM2.5 and PM10 showed a gradual decrease trend at 9h-16h, ie 9h highest and 16h lowest. The AQI fluctuated between 94.2816 and 103.3562 , indicated that the air quality at $9 \mathrm{~h}-16 \mathrm{~h}$ was good or slightly polluted. (4) The spatial distribution of AQI, PM2.5 and PM10 was characterized by low northwest and high southeast, and the southeastern part was gradually decreasing from 9h-16h. AQI was negatively correlated with elevation. The higher the elevation, the better the air quality, and the worse the air quality.
\end{abstract}

\section{INTRODUCTION}

With the rapid development of the economy in the Beijing-Tianjin-Hebei region, the problem of air pollution became increasingly serious(Iii et al.,2002). Air pollution became an important environmental issue in the Beijing-Tianjin-Hebei region. In 2012, the national Air Quality Index (AQI) was used to evaluate the urban air quality level. The AQI classification calculation refers to the new ambient air quality standard (GB3095-2012), mainly using sulfur dioxide $\left(\mathrm{SO}_{2}\right)$ and nitrogen dioxide $\left(\mathrm{NO}_{2}\right)$, carbon monoxide $(\mathrm{CO})$, ozone $\left(\mathrm{O}_{3}\right)$, and PM10, PM2.5 and other six pollutant concentration values to convert into corresponding indexes, which can be used for environmental status assessment, trend evaluation and retrospective evaluation, providing timely and accurate Air quality. Compared with the previous Air Pollution

\footnotetext{
* Corresponding author:Juanli Jing,

Email: jjlgut2008@163.com
}

Index (API), AQI has stricter grading standards. More pollutants are monitored and the evaluation results are more objective(Kang et al.,2017).

In recent years, air quality issues have received increasing attention from scholars at home and abroad. Holland et al.(2004) studied the $\mathrm{SO}_{2}$ concentration in the central and western regions, and the results showed that the $\mathrm{SO}_{2}$ concentration decreased continuously in the past 10 years, and the air quality in the region was significantly improved. Du et al. (2017) used AQI to compare the spatial variation of 74 cities in China, analyzed the AQI grade distribution and spatial differences of air quality in the region, and constructed a model of the influencing factors of air quality index. Puustinen et al. (2007) studied the number of airborne particles in European cities. The results showed that urban air pollution was affected by particulate matter, but the average urban air pollution level could not be measured by the concentration of particulate matter at a certain location. Zhang et al.(2011) used GIS technology to study the spatial and temporal distribution characteristics of air quality in China and the Pearl River Delta. 
The result showed that air pollution had spatial agglomeration characteristics and significant seasonal variation characteristics. Farzanegan et al.(2011)studied the air quality of 122 countries and combined the new air quality evaluation criteria to rank the air quality of each country in the past 20 years. The results showed that air quality was inseparable from urban industrialization and energy consumption. Xiao et al. (2018) discussed the influencing factors of air quality, and the results showed that population concentration, energy consumption and industrialization had a deteriorating effect on China's air quality. The existing research mainly focused on the spatial and temporal evolution characteristics and influencing factors of air quality (Jiang et al.,2018;Xu et al.,2019;). Zhan et al. (2014) used air quality monitoring data combined with inverse distance weighted interpolation to analyze the spatial and temporal distribution of $\mathrm{AQI}$ in Wuhan and the correlation between AQI and other six major pollutants. The monthly AQI performance of Wuhan City was characterized by obvious spatial and temporal distribution characteristic, and AQI had the greatest correlation with PM2.5. Liu et al. (2016) used AQI and 6 major pollutants as research objects, and used Gini coefficient measurement and spatial statistical analysis method to analyze the characteristics of urban air pollution in China. The results showed that China's urban air pollution presents significant autocorrelation characteristics, and air pollution was characterized by Geographical aggregation and spatial non-equilibrium characteristics. Chen et al. (2017) analyzed the temporal and spatial distribution characteristics of AQI and air content factors in the Yangtze River Delta urban agglomeration. The results showed that AQI was the best in summer, the worst in winter, and the spatial distribution was characterized by low south and high north. There was significant correlation between AQI and PM2.5. Pei et al. (2018) used air quality monitoring data combined with spatial autocorrelation analysis to analyze the temporal and spatial distribution characteristics of AQI in Shenzhen.The results showed that AQI was positive spatial autocorrelation, and the primary pollutants were different every year. AQI was the best in summer and the worst in winter.Previous studies have mainly analyzed the temporal and spatial distribution of AQI from the daily, seasonal and annual scales, and rarely involved hourly scales. Therefore, this paper selected the Beijing-Tianjin-Hebei region with developed economy and high industrial population as the research area, and used AQI calculation method and statistical correlation evaluation method to study the characteristics of AQI and analyze the correlation between AQI and PM particle concentration and hourly temporal and spatial distribution.

\section{STUDY AREA AND DATASETS}

\subsection{Study Area Characteristics}

The Beijing-Tianjin-Hebei region is located in the eastern coastal areas of China and north of the North China Plain. It faces the Bohai sea in the east, Inner Mongolia in the northwest, and the North China Plain in the south.The area is between the longitudes of $113^{\circ}$ to $12^{\circ} \mathrm{E}$ and latitudes of $36^{\circ}$ to $43^{\circ} \mathrm{N}$, with a total area of $21.54 \mathrm{~km}^{2}$, including Beijing, Tianjin and Hebei provinces. As shown in Figure 1, the terrain of the Beijing-Tianjin-Hebei region is high in the northwest, low in the southeast, and average in the northwest is $1500 \mathrm{~m}$. Its climatic conditions are temperate continental monsoon climate, hot and humid in summer and dry and cold in winter. The Beijing-Tianjin-Hebei region is the core of economic development in northern China. Due to the high population density, the pollution caused by industrial production and exhaust emissions is serious, causing ash weather, resulting in reduced visibility, affecting people's daily lives and endangering human health.

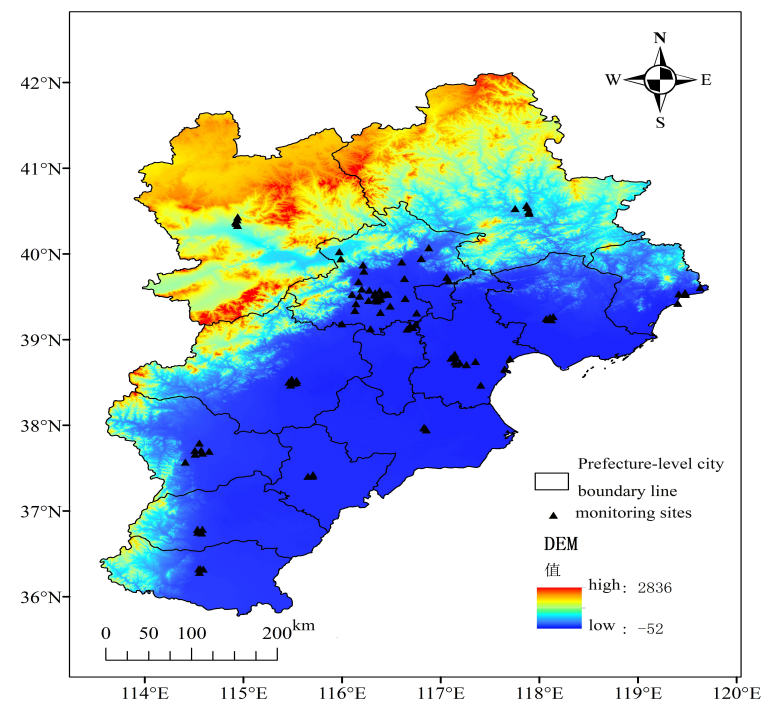

Figure 1. Distribution of ground-based monitoring stations in the Beijing-Tianjin-Hebei region

\subsection{Research Data}

The paper collected AQI and related pollutant datas from the Beijing-Tianjin-Hebei region published by the official website 
of China Environmental Monitoring Center from July 2015 to July 2018 (http://www.cnemc.cn/), including nitrogen dioxide (NO2). ), ozone (O3), nitric oxide (CO), sulfur dioxide (SO2), PM2.5, and respirable particulate matter (PM10). Near-surface data was calibrated and quality controlled according to China's environmental protection standards (HJ618-2011) (Liu et al.,2014). The Beijing-Tianjin-Hebei region included 102 ground-based monitoring stations. The spatial distribution was shown in Figure 1. The DEM (Digital Elevation Model) data was selected from the SRTM (Shuttle Radar Topography Mission) Space Shuttle Radar Topography Mission 90m resolution digital elevation data from the Geospatial Data Cloud website (http://www.gscloud.cn/search) .

\section{RESEARCH METHODS}

\subsection{AQI Calculation Method}

\begin{tabular}{|c|c|c|c|c|c|c|}
\hline AQI & $\begin{array}{c}\mathrm{SO}_{2} \\
\text { concentration } \\
\text { (daily average) } \\
\mu \mathrm{g} / \mathrm{m} 3\end{array}$ & $\begin{array}{c}\mathrm{NO}_{2} \\
\text { concentration } \\
\text { (daily } \\
\text { average) } \\
\mu \mathrm{g} / \mathrm{m} 3\end{array}$ & $\begin{array}{c}\text { PM2.5 } \\
\text { concentration } \\
\text { (daily } \\
\text { average) } \\
\mu \mathrm{g} / \mathrm{m} 3\end{array}$ & $\begin{array}{c}\text { PM10 } \\
\text { concentration } \\
\text { (daily average) } \\
\mu \mathrm{g} / \mathrm{m} 3\end{array}$ & $\begin{array}{c}\mathrm{O}_{3} \\
\text { concentration } \\
(1 \text { hour } \\
\text { average }) \\
\mu \mathrm{g} / \mathrm{m} 3\end{array}$ & $\begin{array}{c}\text { CO concentration } \\
\text { (daily average) } \\
\mu \mathrm{g} / \mathrm{m} 3\end{array}$ \\
\hline 0 & 0 & 0 & 0 & 0 & 0 & 0 \\
\hline 50 & 50 & 40 & 35 & 50 & 160 & 2 \\
\hline 100 & 150 & 80 & 75 & 150 & 200 & 4 \\
\hline 150 & 475 & 180 & 115 & 250 & 300 & 14 \\
\hline 200 & 800 & 280 & 150 & 350 & 400 & 24 \\
\hline 300 & 1600 & 565 & 250 & 420 & 800 & 36 \\
\hline 400 & 2100 & 750 & 350 & 500 & 1000 & 48 \\
\hline 500 & 2620 & 940 & 500 & 600 & 1200 & 60 \\
\hline
\end{tabular}

Table 1. Air pollutant concentration limits

\subsection{Correlation Evaluation Method}

(1) The formula of the pearson correlation coefficient (R) can be expressed as(Zhang et al.,2014):

$$
\mathrm{R}_{\mathrm{xy}}=\frac{\sum_{i=1}^{n}\left(x_{i}-\bar{x}\right)\left(y_{i}-\bar{y}\right)}{\sqrt{\sum_{i=1}^{n}\left(x_{i}-\bar{x}\right)^{2}} \sqrt{\sum_{i=1}^{n}\left(y_{i}-\bar{y}\right)^{2}}}
$$

(1)The formula of AQI can be expressed as

$$
\mathrm{AQI}=\max \left\{\left(\mathrm{IAQI}_{1}, \mathrm{IAQI}_{2}, \ldots \ldots . . \mathrm{IAQI}_{\mathrm{n}}\right)\right\}
$$

Where IAQI = the Individual Air Quality Index $\mathrm{n}=$ the pollution project, which generally includes NO2, CO, SO2, O3, PM2.5 and PM10. Among them, the largest IAQI of the six monitoring projects, as the day of AQI (Jin et al.,2014). (see Table 1.)

(2)The formula of IAQI can be expressed as:

$$
I A Q I=\frac{I_{h}-I_{l}}{C_{h}-C_{l}}\left(C-C_{l}\right)+I_{l}
$$

Where $\quad \mathrm{Il}$ and $\mathrm{Ih}=\mathrm{AQI}$ limits

$\mathrm{Ch}$ and $\mathrm{Cl}=$ the pollutant concentration limits

$\mathrm{C}=$ the input value, the pollutant concentration 
The root mean square error is used to measure the deviation between the observed value and the true value.

\section{RESULTS}

\subsection{AQI Variation Characteristic}

The average value of AQI in Beijing-Tianjin-Hebei region during July 2015 to July 2018 was 97.6577 . It could be seen from Table 2. that the air quality level was grade II and the overall performance was good. The $9 \mathrm{~h}-16 \mathrm{~h}$ data was Averaged as the daily average daily value, and the ratio of the number of days of AQI in the
Beijing-Tianjin-Hebei region to the total number of days was calculated, so as to obtain the distribution frequency of different air quality levels in the Beijing-Tianjin-Hebei region.It could be seen from Figure 2 that the AQI was the second/good distribution frequency (40\%), which was $2 / 5$ of the total research scale days.The air quality was the first/optimal distribution frequency, which was $24 \%$ and the air quality was the sixth/severe pollution had the lowest frequency and its value was $2 \%$. Overall, the air quality compliance rate was $64 \%$ (ie, air quality performance was excellent or good).

\begin{tabular}{|c|c|c|c|c|}
\hline AQI & AQI level & air quality condition & color & health effects \\
\hline $0-50$ & level 1 & excellent & green & Can go out and absorb fresh air \\
$50-100$ & level 2 & good & yellow & Normal outdoor activities \\
$100-150$ & level 3 & mild pollution & orange & Sensitive people reduce intense outdoor activities \\
$150-200$ & level 4 & moderately polluted & red & Increased symptoms in sensitive population \\
$250-300$ & level 5 & heavy pollution & purple & Everyone reduces outdoor activities \\
$>300$ & level 6 & severe pollution & maroon & Everyone reduces outdoor activities \\
\hline
\end{tabular}

Table 2. Air quality index grading
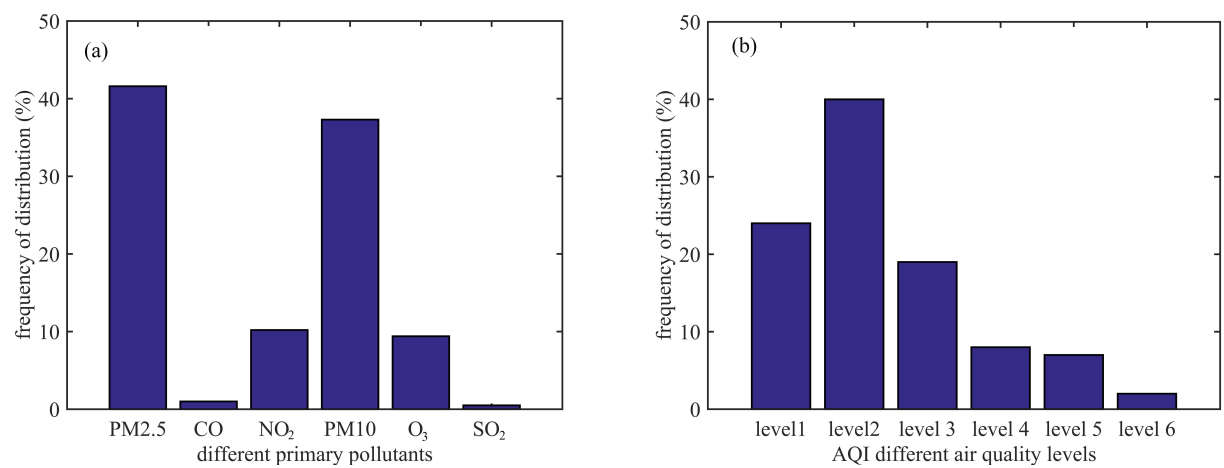

Figure 2. Distribution frequency of different air quality grades/levels of AQI in Beijing-Tianjin-Hebei region and distribution frequency of primary pollutants different from AQI

The AQI value in the study scale was from 0 to 50 , the air quality was excellent, and there was no primary pollutant. It could be seen from Figure. 2 that the most frequent distribution of primary pollutants in the Beijing-Tianjin-Hebei region was PM2.5, which was $41.6 \%$, indicating that fine particulate matter dominated air pollution; followed by PM10, which had a value of $37.3 \%$. The distribution frequency of PM2.5 and PM10 was $78.9 \%$, which indicated that the air quality pollution was mainly polluted by fine and coarse particles, and other pollutants had little impact on air quality in Beijing-Tianjin-Hebei region.

\subsection{Analysis of Correlation Between AQI and PM2.5, PM10}

From the above-mentioned distribution characteristics of primary pollutants, the air pollution mainly came from PM2.5 
and PM10 in Beijing-Tianjin-Hebei region. In order to further study the correlation between AQI and PM2.5 and PM10, linear fitting of AQI with PM2.5 and PM10 was carried out. It could be seen from Figure $3 \mathrm{a}$ and $3 \mathrm{~b}$ that $\mathrm{AQI}$ had a significant positive correlation with PM2.5 and PM10 $\left(\mathrm{R}^{2}=0.8225, \mathrm{p}<0.01\right.$;

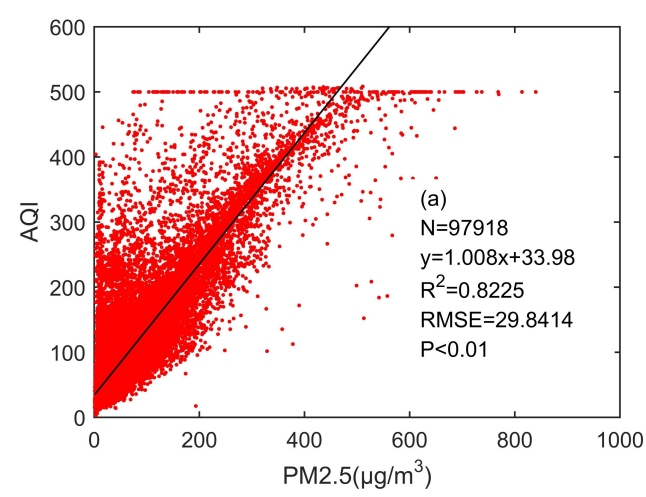

$\left.\mathrm{R}^{2}=0.7749, \mathrm{p}<0.01\right)$. Overall, the correlation between AQI and PM2.5 was better. The correlation between AQI and PM10 indicated that the fine particle pollution of Beijing-Tianjin-Hebei had a great impact on air quality.

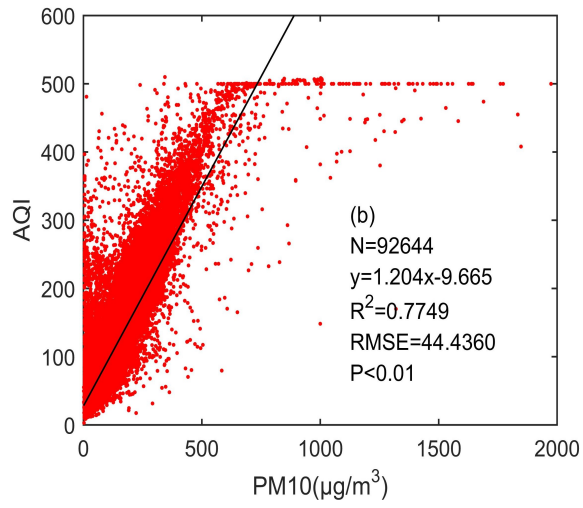

Figure 3. Linear fitting of AQI with PM2.5 and PM10

\subsection{Temporal and Spatial Variation Characteristics of AQI and PM2.5, PM10}

\subsubsection{AQI and PM2.5, PM 10 hour variation characteristics:}

MATLAB was used to program and draw a two-coordinate graph to analyze the hourly changes of AQI, PM2.5 and PM10 from July 2015 to July 2018 in Beijing-Tianjin-Hebei region. As could be seen from Figure.5, the PM2.5 and PM10 values fluctuated between $55-70 \mu \mathrm{g} / \mathrm{m}^{3}$ and $60-120 \mu \mathrm{g} / \mathrm{m}^{3}$, respectively, and the AQI was a dimensionless value with a value of 94-10.The values of AQI, PM2.5 and PM10 from 9h to $16 \mathrm{~h}$ showed a decreasing trend, and the variation of PM10 was larger than that of AQI and PM2.5.The AQI had the lowest value at $16 \mathrm{~h}$, which was 94.2816 , and the air quality was good. The highest value was 103.3562 at $9 \mathrm{~h}$, and the air quality was mildly

polluted.

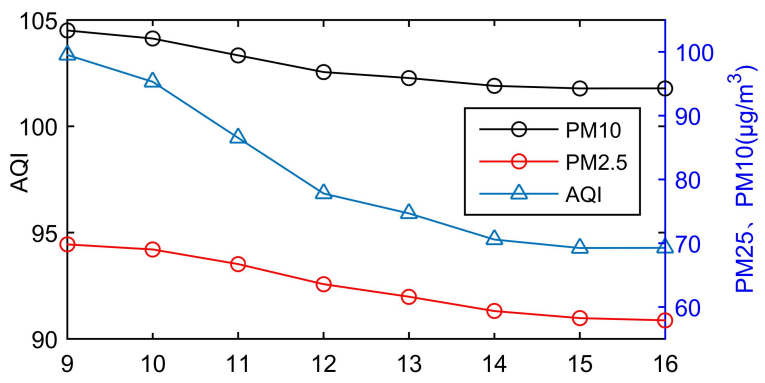

Figure 4. AQI, PM2.5 and PM10 hour line chart

4.3.2 Hourly Spatial Distribution Characteristics of AQI, PM2.5 and PM10 :Based on 102 air quality monitoring stations in Beijing-Tianjin-Hebei region, kriging interpolation was carried out by using ArcGIS software to obtain the hourly variation data of AQI, PM2.5 and PM10.It could be seen from Figure 5 that the spatial distribution of AQI, PM2.5 and PM10 in $9 \mathrm{~h}-16 \mathrm{~h}$ generally showed the characteristics of low in northwest and high in southeast, showing a gradually decreasing trend from 9h-16h(Tian et al.,2019).Among them, the high value areas of AQI, PM2.5 and PM10 were concentrated in the southern part of Beijing, Tianjin and Hebei, and the hourly AQI range was 100-140, and the air quality was slightly polluted.The variation range of PM2.5 and PM10 was $55-105 \mu \mathrm{g} / \mathrm{m}^{3}$ and $100-200 \mu \mathrm{g} / \mathrm{m}^{3}$ respectively. The air quality in this area was the worst. Vehicles with heavy pollution industrial activities and high energy consumption were the main human factors. The low-value areas of AQI, PM2.5 and PM10 were mainly distributed in Zhangiiakou, Chengde, Qinhuangdao and northwest Beijing. The hourly AQI range was from 0 to 90 , and the air quality was excellent. PM2.5 and PM10 fluctuate mainly between $0-55 \mu \mathrm{g} / \mathrm{m}^{3}$ and $0-120 \mu \mathrm{g} / \mathrm{m}^{3}$. The area had more trees and reservoirs, lower population density and energy intensity, and the best air quality. 

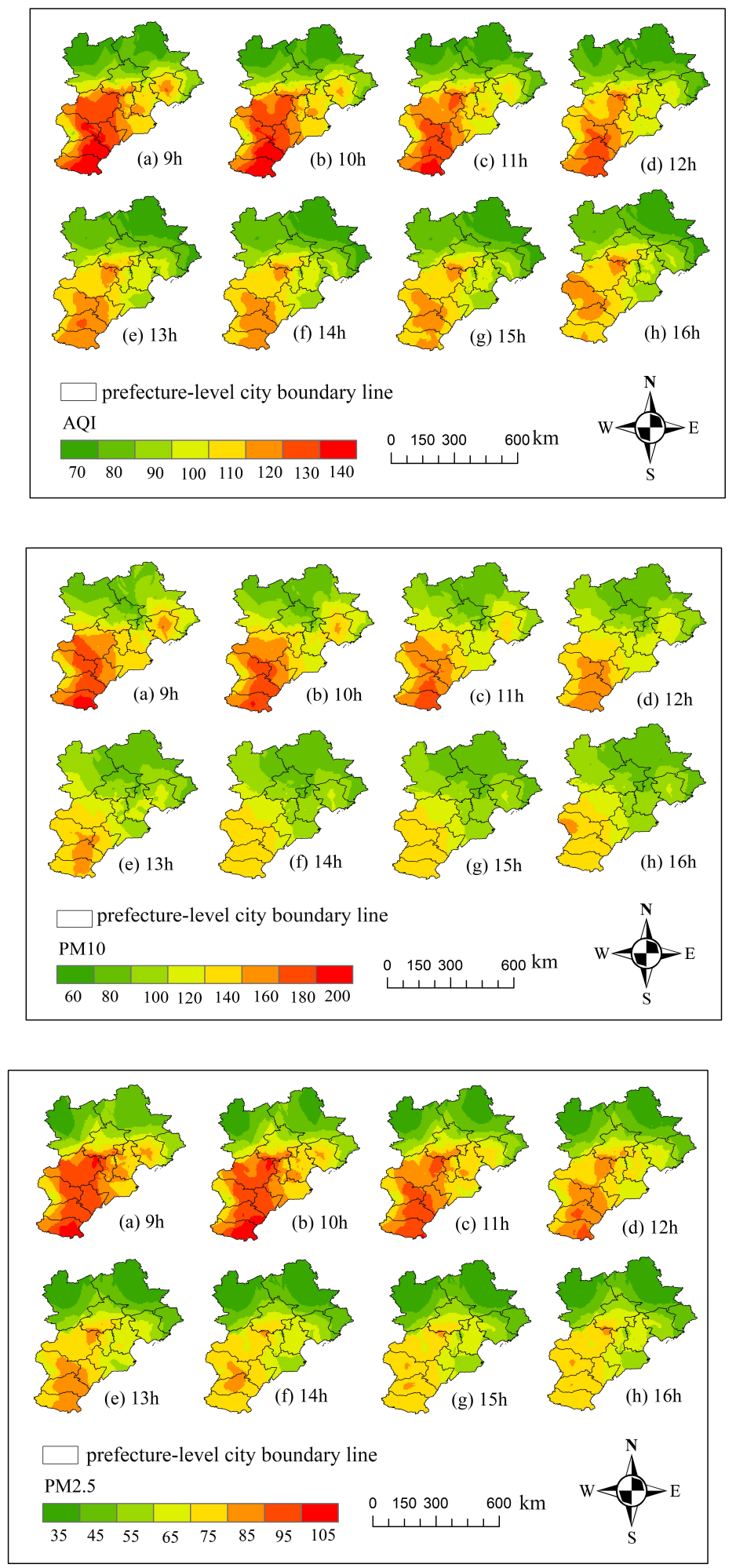

Figure 5. AQI, PM10 and PM2.5 9h-16h hourly spatial distribution map

In addition, AQI, PM2.5 and PM10 were consistent at high and low values, ie the highest overall value at $9 \mathrm{~h}$, especially in the southeast, with the lowest at $16 \mathrm{~h}$. This may be because the surface temperature dropped rapidly at night, and the temperature of the near-surface air layer dropped slowly, forming an inverse temperature phenomenon. It made the city's polluted air unable to spread upwards, resulting in greater pollution in the morning $9 \mathrm{~h}$. In addition, $9 \mathrm{~h}$ was also the peak period of travel. At this time, the vehicles were dense, and the exhaust emissions were larger than other times.

In order to further study the influence of elevation on air quality, this paper analyzed the relationship between elevation and AQI, 
PM2.5 and PM10 based on DEM data.It could be seen from Table 3. that the elevation of $9 \mathrm{~h}-16 \mathrm{~h}$ was negatively correlated with AQI, PM2.5 and PM10, which was significantly negatively correlated in some time. This indicated that the higher the altitude in the Beijing-Tianjin-Hebei region, the lighter the particulate matter pollution and the better the air quality.From $9 \mathrm{~h}$ to $16 \mathrm{~h}$, the correlation coefficients between elevation and AQI, PM2.5 and PM10 gradually decreased.,which had certain regularity, and the simple linear function can not describe its relationship in depth.On the other hand, the vegetation coverage of the Yanshan Mountains and the Taihang Mountains was larger than that of the urban areas. Plants can reduce the impact of dust on the atmosphere by covering the ground, and can also adsorb atmospheric particles to make the particles achieve sedimentation and thus reduce air pollution(Li et al.,2011).Therefore, upgrading industrial technology, integrating urban green space and optimizing landscape patterns can minimize urban air pollutant emissions(Deng et al.,2013).

\begin{tabular}{|c|cc|cc|cc|}
\hline \multirow{2}{*}{ hour } & \multicolumn{2}{|c|}{ DEM_AQI } & \multicolumn{2}{c|}{ DEM_PM2.5 } & \multicolumn{2}{c|}{ DEM_PM10 } \\
& $\mathrm{R}$ & RMSE & $\mathrm{R}$ & RMSE & $\mathrm{R}$ & RMSE \\
\hline $9 \mathrm{~h}$ & $-0.6995^{* *}$ & 14.0954 & $-0.7451^{* *}$ & 12.2819 & $-0.6022^{*}$ & 23.2301 \\
$10 \mathrm{~h}$ & $-0.6721^{*}$ & 14.6260 & $-0.7313^{* *}$ & 12.1910 & $-0.5709^{*}$ & 23.6199 \\
$11 \mathrm{~h}$ & $-0.6384^{*}$ & 14.4857 & $-0.7113^{* *}$ & 12.1085 & -0.5157 & 23.5131 \\
$12 \mathrm{~h}$ & $-0.5797^{*}$ & 14.3962 & $-0.6821^{*}$ & 11.7218 & -0.4454 & 22.9208 \\
$13 \mathrm{~h}$ & -0.5396 & 14.1919 & $-0.6623^{*}$ & 11.4486 & -0.4006 & 21.8605 \\
$14 \mathrm{~h}$ & -0.5313 & 13.7329 & $-0.6575^{*}$ & 10.9857 & -0.3804 & 21.2511 \\
$15 \mathrm{~h}$ & -0.5206 & 13.5650 & $-0.6423^{*}$ & 10.8765 & -0.3764 & 20.8434 \\
$16 \mathrm{~h}$ & -0.4990 & 13.6595 & $-0.6344^{*}$ & 10.6270 & -0.3489 & 21.1442 \\
\hline
\end{tabular}

Table 3. The correlation between DEM and AQI, PM2.5 and PM10.

\section{CONLUSIONS}

1. The average AQI in the Beijing-Tianjin-Hebei region within three years was 97.6577 , and the air quality compliance rate was $67 \%$. During this period, the primary pollutants were PM2.5 and PM10, which accounted for $78.9 \%$ of the distribution frequency of the six pollutants, indicating that PM2.5 and PM10 had a greater impact on the air quality of Beijing-Tianjin-Hebei.

2. AQI showed significant positive correlation with PM2.5,PM10 were characterized by low northwest and high southeast. In addition, AQI and PM2.5, PM10 were closely related to elevation and vegetation coverage, and had a significant negative correlation with the overall elevation. The higher the elevation, the better the air quality. Conversely, the worse the air quality.

3. AQI was consistent with the hourly change trend of PM2.5 and PM10, showing a gradually decreasing trend from $9 \mathrm{~h}$ to 16h. Air quality fluctuated in the $9 \mathrm{~h}-16 \mathrm{~h}$ from good to light pollution.The spatial distribution of AQI, PM2.5 and PM10, and $\mathrm{R}^{2}$ was 0.8225 and 0.7749 , respectively.Overall, the former was better than the latter, indicating that the Beijing-Tianjin-Hebei region was greatly affected by the pollution of fine particles.

4. In addition to elevation and vegetation coverage, AQI is also affected by meteorological factors and socio-economic factors such as relative humidity, temperature, wind speed, per capital GDP, population density, and energy consumption. Future research work can focus on the relationship between AQI and influencing factors.

\section{ACKNOWLEDGMENTS}

This research was financially supported by Guangxi Key Laboratory of Spatial Information and Geomatics (16-380-25-08), Guangxi young and middle-aged teacher's basic ability improvement project (KY2016YB192). 


\section{REFERENCES}

Chen, Y. L., Tao, T. H., Ding, P., 2017. Spatial-temporal distribution characteristics of air quality in the urban agglomeration of the yangtze river delta. Resources and Environment in The Yangtze Basin, 26(05), 42-52.

Deng, X. B., 2013. Causes and measures of air pollution in china. Environment and Development, 29(2), 142-144.

Du, G. X., 2017. Research on variation trends and space difference based on aqi of Beijing-Tianjin-Hebei urban agglomeration. Urban Development Research, (08), 55-62.

Farzanegan, M. R., Buehn, A., 2011. Hold your breath: A new index of air quality. Working Papers, 11(24).

Holland, D. M., Smith. C. L., 2004. Regional trends in rural sulfur concentrations. Atmospheric Environment, 38(11), 1673 1684.

Jiang, L., Zhou, H. F., Ba, L., Wang, Z. J., 2018. The spatio-temporal variation of air quality index of cities in China. Economic Geography, 38(9), 87-95.

Jin, H., Fu, Q., Wu, X. F., Yao, Y. W., 2014. Uncertainty in determination of PM2.5 in ambient air by gravimetric method. Environmental Monitoring in China , 30(6), 32-35.

Kang, H. Y., Liu, Y. L., Li, T., 2017. Characteristics of AQI index and its relationship with meteorological elements in key cities of Heilongjiang province. Journal of Natural Resources, 32(4), 692-703.

Li, Y.M., Li, M. L., Jiao, Z. K., 2011. Econometric analysis of influencing factors of air quality in Beijing. China Urban Economy, (9), 260-261.

Liu, H. J., Du, G. J., 2016. Spatial pattern and distributional dynamics of urban air pollution in China an empirical study based on AQI and six sub-pollutants of 161 cities. Economic Geography, 36(10),33 -38.

Liu, P., 2014. How to understand the calculation formula of air quality sub-index (IAQI) and quick calculation. Heilongjiang
Environmental Journal, 38(2), 25-27.

Mou, J. F., Zhao, X., Fan, J. J., Yan, Z. Y., Zen, D., Luo, W. L., Fan, Z. W., 2018. Temporal and spatial distribution of air pollution in Shenzhen city during 2014-2016. Journal of Hygiene Research, 47(2), 270-276.

Pope, C. A., Burnett, R. T., Thun, M. J., Calle, E. E., 2002. Lung cancer, cardiopulmonary mortality, and long term exposure to fine particulate air pollution. Jama, 287(9), 1132-1141.

Puustinen, A., Himer, K., Pekkanen, J., 2007. Spatial variation of particle number and mass over four European cities. Atmospheric Environment , 41 (31), 6622-6636.

Tian, Y. L., Jiang, Y., Liu, Q., Xu, D. X., Zhao, S. D., He, L .H., Liu, H. J., Xu, H., 2019. Temporal and spatial trends in air quality in Beijing. Landscape And Urban Planning, 185, $35-43$

Xiao, Y., Tian, Y. Z., Xu, W. X., Liu, J., Wan, Z. Y., Zhang, X. Q., Liu, X.D., 2018. Study on the spatio-temporal characteristics and socioeconomic driving factors of air pollution in China. Ecology and Environmental Sciences, 27(3), 518-526.

Xu, Y. T., Liu, X. Z., Wang, Z. B., 2019. Spatial-temporal distribution characteristics of air quality in Chinese cities based on the AQI index. Journal of Guangxi Normal University (Natural Science Edition) , 37(1), 187-196.

Zhan, C. G., Wu, Y., Wei, S. Z., Tu, L. L., 2014. Temporal and spatial distribution of AQI in Wuhan based on GIS. Geospatial Information, 12(5), 62-64.

Zhang, B. C., Chen, Y. J., Li, W. W., Chen ,H. M., Luo, J. H., 2011. Temporal and spatial characteristics of air quality in the Pearl River Delta region based on GIS. Ecology And Environmental Sciences, 20(4), 600-605.

Zhang, J. Y., Gao, W., Hu, J., Zheng, Y., 2014. Comparison of grey correlation and pearson correlation coefficients. Journal of Chifeng University (Natural Science Edition), (21), 1-2. 